\title{
Sustentabilidade e energia eólica: percepções comunitárias no interior do Ceará - Brasil
}

Roseilda Nunes Moreira ${ }^{1}$ Fabiana Pinto de Almeida Bizarria ${ }^{2}$ Fábio Freitas Schilling Marquesan ${ }^{3}$ Flávia Lorenne Sampaio Barbosa ${ }^{4}$

\section{Resumo}

Este artigo trata do processo de implementação de empreendimentos de produção de energia eólica, bem como suas consequências em termos de sustentabilidade socioambiental e econômica. O objetivo do artigo é investigar os impactos socioambientais e econômicos na instalação e funcionamento de parques eólicos nos municípios de Itarema e Acaraú (Ceará), na perspectiva da comunidade. Configura-se como uma pesquisa exploratória e compreensiva, de natureza qualitativa, com suporte em dados coletados em entrevistas presenciais semiestruturadas, pesquisa bibliográfica e documental e registros de diário de campo. Para o tratamento dos dados, utilizou-se a técnica de análise de conteúdo, com auxílio do software Atlas.ti para categorização. Consideraram-se os dados com suporte no modelo de adaptação estratégica de Pettigrew (1987; 2012), que compreende a elaboração de análises com base na leitura de três conceitos - "conteúdo", "contexto" e "processo". Constata-se que da implantação dos parques resultou um importante impacto ambiental, que trouxe como consequência, dentre outras, a degradação de um ambiente - no caso, o manguezal - utilizado como fonte de renda por uma comunidade.

Palavras-chave: Energia eólica. Desenvolvimento sustentável. Impactos socioambientais. Impactos econômicos.

\section{Abstract}

The article deals with the process of implementation of wind power generation ventures, as well as its consequences in terms of social and environmental and economic sustainability. The objective of this article is to investigate the environ-

${ }^{1}$ Doutoranda em Administração na Universidade de Fortaleza (Unifor). Professora da Faculdade 7 de Setembro. bianapsq@hotmail.com

2 Doutoranda em Administração na Universidade de Fortaleza (Unifor). bianapsq@hotmail.com

${ }^{3}$ Doutor em Administração. Professor Adjunto do Programa de Pós-Graduação em Administração da Universidade de Fortaleza (PPGA/Unifor). bianapsq@hotmail.com

${ }^{4}$ Doutoranda em Administração na Universidade de Fortaleza (Unifor). Professora do Curso de Administração da Universidade Federal do Piauí (UFPI). bianapsq@hotmail.com 
mental and economic impacts on the installation and operation of wind farms in the municipality of Itarema and Acaraú (Ceará), from the perspective of the community. Appears as an exploratory research and descriptive qualitative in nature, supported by data collected in face-to-face interviews, bibliographical research and semi-structured documents and records of field journal. For the treatment of the data we used the technique of content analysis, with the help of Atlas.TI software for categorization. It was considered the data model supports strategic adaptation Pettigrew $(1987,2012)$ that comprises the elaboration of analyses from the reading of three concepts "content", "context" and "process". It is noted that the deployment of the parks resulted in a significant environmental impact, and that this brought consequences, among others, the deterioration of an environment used as a source of income for the community, in this case, the mangrove forest.

Keyword: Wind energy. Sustainable development. Environmental impacts. Economic impacts.

\section{Introdução}

Aspectos ambientais e sociais que delimitam a proposta de desenvolvimento sustentável emergiram como contraponto à perspectiva do desenvolvimento unicamente econômico (SINAY et al., 2013), sendo fruto dos trabalhos da Comissão Mundial sobre o Meio Ambiente e Desenvolvimento (CMMAD) da Organização das Nações Unidas (ONU), por meio do Relatório de Brundtland, o qual definiu, em 1987, o desenvolvimento sustentável como um processo de satisfação de necessidades presentes, com o compromisso de que essas necessidades serão supridas no futuro (MEBRATU, 1998; SINAY et al., 2013).

Nos anos seguintes, ações em níveis global, nacional e local destacaram determinados aspectos dos desafios ambientais, reclamando um novo olhar sobre a relação ser humano/meio ambiente, transformando-se em tema dominante (SINAY et al., 2013; GONÇALVES-DIAS; HERRERA; CRUZ, 2013). Destacou-se a investigação sobre o prisma da educação para o desenvolvimento sustentável nos últimos 20 anos, tendo como cenários, por exemplo, a Conferência Rio+20, Cúpula da Terra (SULAIMAN, 2011; HOPKINS, 2012), que "[...] levou à produção dos principais documentos internacionais, como a Declaração do Rio, a Agenda 21 e as convenções sobre a desertificação, a biodiversidade, e as mudanças climáticas" (MEBRATU, 1998, p. 502).

No entanto, as definições sobre desenvolvimento sustentável e sustentabilidade ainda são imprecisas, em virtude de as abordagens traduzirem especificidades de cada área específica do conhecimento. No entanto, as discussões, fruto dessa diversidade, têm influenciado a elaboração de políticas de governos, de agências internacionais e de organizações empresariais (MEBRATU, 1998; REDCLIFT, 2006).

Nos anos 2000, a perspectiva da sustentabilidade ganhou destaque nas 
universidades, empresas, pautas governamentais e na sociedade, com suporte no discurso da gravidade da degradação ambiental, emergindo uma leitura catastrófica e, em contrapartida, a necessária onda verde, adotada como expectativa à responsabilidade socioambiental e, no âmbito organizacional, à possibilidade de maior vantagem competitiva (COSTA et al., 2013; LASH; WELLINGTON, 2007).

No âmbito da administração, dada a relevância do papel das empresas como geradoras de sustentabilidade, três premissas são apresentadas por Banerjee (2008): 1) como empresas devem pensar além de fazer dinheiro e observar o desenvolvimento social e questões ambientais; 2) como empresas devem se comportar de forma ética e demonstrar integridade e transparência em suas operações; 3) como empresas devem se envolver com a comunidade de forma a melhorar o bem-estar social e apoiar a comunidade por meio da filantropia, por exemplo.

Desse cenário, emerge a questão das fontes energéticas, com importância cada vez mais acentuada no cenário mundial. No que tange à energia eólica, estudos de Meireles, Silva e Thiers (2006), Meireles (2008; 2011), Lage e Barbieri (2001) defendem que sua produção seja baseada em uma política planejada em relação aos aspectos sociais/ambientais e aos impactos ambientais e a medidas mitigadoras.

Nesse sentido, Meireles (2011) evidencia aspectos preocupantes quanto à maneira como os empreendimentos estão sendo implantados e quanto à sua sustentabilidade, especialmente no Nordeste brasileiro, haja vista a inserção de usinas de forma descontrolada, sem monitoramento integrado nem definição dos impactos cumulativos.

Por conseguinte, o estudo é guiado pela questão: Qual a percepção sobre os impactos socioambientais e econômicos de parques eólicos nos municípios de Itarema e Acaraú (Ceará) por parte da comunidade circunvizinha? Para responder ao questionamento da pesquisa, tem-se como objetivo investigar os impactos socioambientais e econômicos na instalação e no funcionamento de parques eólicos nos municípios de Itarema e Acarau (Ceará), sob a perspectiva das comunidades onde os parques estão inseridos.

\section{Notas críticas sobre desenvolvimento sustentável e energia eólica}

A pressão mundial sobre os governos e as empresas, em virtude da crescente degradação da natureza e do clamor mundial acerca dos riscos que pesam sobre a vida humana, fazem com que todos ampliem esforços para conferir sustentabilidade ao desenvolvimento. Vivemos uma crise atual gerada pela visão basicamente antropocêntrica de desenvolvimento, que, tradicionalmente, tem dicotomizado homem e natureza, e, por isso, não pode ser considerada sustentável (CARRIERI, 2003; INGOLD, 2000).

Práticas capitalistas contemporâneas contribuem para a desapropriação, ou espoliação e subjugação da vida ao poder da morte numa variedade de contextos (BANERJEE, 2008). Há fortes evidências de que o atual modelo de produ- 
ção para o mercado, em contraponto à produção para a subsistência, tem papel fundamental na degradação ambiental (SAHLINS, 1978). Assim, observa-se que a lógica do sistema de produção e consumo imperante está em contradição com a sustentabilidade.

O ideal desenvolvimentista de prosperidade e progresso, difundido no discurso capitalista, torna cada vez mais distante a possibilidade de realização da relação sociedade-natureza, trazendo também diversas consequências, dentre as quais o problema ambiental (SACHS, 2000). No que diz respeito à lógica da harmonia indivíduo-ambiente, o desenvolvimento sustentável se apresenta como um processo de mudança em que a exploração de recursos, a direção dos investimentos, a orientação do desenvolvimento tecnológico e a mudança institucional podem estar em harmonia quando reforçam o potencial atual e futuro para atender às necessidades humanas. Assim, dois aspectos ressaltam o necessário envolvimento do indivíduo e dos valores que subjazem à ação sustentável: a filosofia, que sustenta as relações entre os diferentes fatores e que deve ser compartilhada em um consenso público; e um sistema abrangente, de tal forma que as inter-relações complexas possam favorecer a comunicação, o entendimento e o crescimento do conhecimento (BRANDON, 1999).

Portanto, afirma-se a necessidade de abordar o desenvolvimento sustentável do planeta, repensar o modelo de crescimento baseado na cultura do desperdício, levando em consideração questões ambientais, políticas e sociais, tendo em vista a multiplicidade de concepções sobre sustentabilidade e sua vertente no âmbito da gestão, o desenvolvimento sustentável. Constata-se a necessidade de revisitar a relação homem-ambiente, por meio de aprofundamento no debate, com a participação de diversos segmentos da sociedade "[...] acompanhado de um esforço conciliatório, no sentido não de eliminar de uma vez por todas as contradições teóricas e práticas que o marcam, mas de oferecer às suas diferentes perspectivas uma maior possibilidade de coexistência e convergência" (MARCONATTO, 2013, p. 18).

Para o desenvolvimento econômico, a importância da energia foi evidenciada em momentos históricos importantes, como o da crise econômica de 1970, influenciada pela elevação do preço do petróleo no mercado mundial pelas Organizações dos Países Exportadores de Petróleo (Opep) (NASCIMENTO; MENDONÇA; CUNHA, 2012). Nesse contexto, a adoção de energias alternativas tornou-se fator de segurança para o desenvolvimento de diversos países (SIMAS; PACCA, 2013).

Crises econômicas ressaltaram a dependência de energia e a fragilidade dos países diante da utilização de recursos não-renováveis. Do ponto de vista do desenvolvimento econômico, a busca por alternativas energéticas tornou-se vital, como forma de promover a sustentabilidade das organizações e vantagens competitivas por meio de investimentos crescentes em fontes renováveis de energia, para suprir necessidades econômicas e, também, gerar menos impacto ambiental (GOLDEMBERG; LUCON, 2007; SIMAS; PACCA, 2013).

Além das questões econômicas, novas tecnologias de energia também 
estão no bojo de discursões ambientais, considerando que a produção energética mais disseminada ainda tem como elemento primordial recursos não-renováveis, como petróleo, carvão, energia nuclear, os quais provocam impactos ambientais negativos, como a produção de gases de efeito estufa (BARBIERI et al., 2010). Isso posto, "[...] entre possíveis alternativas, a energia eólica é uma que despertou significativa atenção durante as últimas décadas" (SIMAS; PACCA, 2013, p. 99), emergindo como uma proposta tecnológica segura e sustentável (NASCIMENTO; MENDONÇA; CUNHA, 2012).

Particularmente, a energia eólica apresenta maiores vantagens ambientais, quando comparada à das fontes tradicionais, pois sua produção não implica a emissão de $\mathrm{CO} 2$, - nem de outros produtos nocivos ao ambiente (reduzindo o risco do efeito estufa) - , aumenta a oferta de energia, a produção de energia sustentável em longo prazo; reduz a dependência energética externa; cria oportunidades de emprego; desenvolve a economia local; não apresenta variações de preço, nem riscos geopolíticos; e é ilimitada (ABRAMOWSKI; POSORSKI, 2000; ARAÚJO; FREITAS, 2006; BRYCE, 2011).

Diante dessa perspectiva, a energia sustentável condiciona, muitas vezes, a premissa de que a fonte energética renovável não desencadeia impactos socioambientais. No entanto, a implantação desordenada de usinas eólicas no Nordeste brasileiro ocasiona danos socioambientais, sinalizando a importância de uma análise prévia sobre a construção de planejamentos mais eficientes, o que minimizaria possíveis impactos negativos advindos da energia eólica (MEIRELES, 2011).

\section{Energia eólica no Ceará}

A energia eólica tem experimentado crescimento no mundo, e a questão ambiental potencializa os argumentos mais relevantes para essa expansão. Apesar da distribuição ser diferenciada entre os países, o potencial dessa energia é considerado maior que o da produção de energia elétrica no mundo (SIMAS; PACCA, 2013). No caso brasileiro, é estimado um potencial de 300 GWATTS, possuindo alta relevância, haja vista a necessidade de aumento da capacidade nacional instalada (MELLO, 2013).

O perfil energético brasileiro é apresentado com potencial técnico promissor para o emprego de fontes renováveis não tradicionais. Especificamente, a energia eólica evidencia um relevante papel no suprimento de demandas energéticas com foco no desenvolvimento sustentável do país (MOREIRA et al., 2013). Da mesma forma, a produção de energia eólica assume um papel de destaque, atribuído especialmente ao baixo impacto imposto ao ambiente em sua fase de implantação. A essa vantagem soma-se o desenvolvimento de sua base tecnológica e industrial e a experiência operativa acumulada nos últimos anos em todo o mundo (BRASIL, 2011).

No início dos anos de 1990, os primeiros estudos sobre o potencial eólico brasileiro foi realizado pelo Centro Brasileiro de Energia Eólica (CBEE) da Universi- 
dade Federal do Pernambuco (UFPE), com o apoio da Agência Nacional de Energia Elétrica (ANEEL) e do Ministério de Ciência Tecnologia (MCT), tendo como resultado o primeiro Atlas Eólico da Região Nordeste, o qual identificou a ampla e privilegiada faixa litorânea dos estados do Piauí, Ceará, Rio Grande do Norte, Paraíba e Pernambuco como área potencial para instalação de parques eólicos (ANEEL, 2014).

No Ceará, o primeiro parque eólico foi inaugurado em janeiro de 1999, na Praia da Taíba, no município de São Gonçalo do Amarante, tendo a capacidade de $5 \mathrm{MW}$, com dez aerogeradores de 44 metros de altura e $500 \mathrm{KW}$ instalados (FONTENELE; SOUZA, 2004). A segunda usina foi inaugurada em abril do mesmo ano, na Prainha, município de Aquiraz, tendo capacidade para $10 \mathrm{MW}$, com vinte aerogeradores de $44 \mathrm{~m}$ de altura e $500 \mathrm{KW}$ instalados.

As duas, em Taíba e na Prainha, foram as primeiras no mundo construídas sobre dunas, com capacidade de produzir 52,5 GWh/ano, energia suficiente para atender 120 mil habitantes (FONTENELE; SOUZA, 2004). Em 2000, foi instalado o parque eólico do Porto do Mucuripe (Fortaleza), com potência de 2,4 MW. Nesse mesmo ano, foram iniciados estudos para a construção de mais duas usinas eólicas de 30 MW cada, em Paracuru e Camocim (ADECE, 2010).

Em 2004, o Governo do Estado do Ceará lançou o Programa de Incentivo às Fontes Alternativas de Energia Elétrica (PROINFA), por meio do Fundo Constitucional de Financiamento do Nordeste (FNE). Atualmente, segundo dados da ANEEL (2014), o Ceará é o segundo maior produtor de energia eólica do Brasil, perdendo somente para o Rio Grande do Norte. Possui 52 parques com capacidade de produção de $1.140 \mathrm{MW}$, concentrados nos municípios de Aquiraz, Acaraú, Amontada, Aracati, Beberibe, Comocim, Paracuru, São Gonçalo do Amarante e Fortaleza (ADECE, 2010).

O amplo potencial eólico do Estado do Ceará desperta interesse por essa fonte de produção de energia. Os municípios de Acaraú e Itarema, assim como outros municípios no estado, destacam-se por meio de novos empreendimentos empenhados nessa produção de energia. Um dos parques é denominado Central Eólica Volta do Rio S/A. Nesta central, foram instalados 28 aerogeradores, iniciando na Praia do Farol, que é limite entre os municípios de Acaraú e Itarema, e se estendendo até a Praia do Espraiado, estando a subestação de energia localizada na praia da Volta do Rio (OLIVEIRA, 2011).

\section{Metodologia}

Realizou-se estudo de caso, por meio de uma abordagem compreensiva das relações e percepções de um determinado fenômeno, objetivando produzir conhecimento sobre (MINAYO, 2007) a implantação de uma central eólica nos municípios de Acaraú e Itarema, no estado do Ceará. Para tanto, considerando-se que "[...] o caso deve ser tratado com profundidade, buscando o completo entendimento de sua natureza, suas circunstâncias, seu contexto e suas características" (SAMPIERI; COLLADO; LUCIO, 2006, p. 275), busca-se, na leitura dos dados que 
serão coletados, o aprofundamento necessário para elucidar as percepções sobre os impactos socioambientais e econômicos no processo de implantação e manutenção dos aerogeradores nos municípios.

Para a coleta de dados, optou-se pela análise da percepção da comunidade em relação à questão de investigação. Os dados foram coletados por meio de dez entrevistas presenciais semiestruturadas, envolvendo um profissional autônomo, um agricultor, um vigilante, um comerciante, uma dona de casa, um estudante, um aposentado e três professores.

As entrevistas tiveram a finalidade de obter informações em profundidade e que se alinham à perspectiva da entrevista qualitativa (BAUER; GASKELL, 2002; MINAYO, 2007), o que possibilita insights durante as narrativas, indicando problemas e questões não resolvidos, os quais ensejam informações importantes para a análise dos dados (PATTON, 2002). Também foi realizada uma pesquisa documental, num diário de campo, em relatórios e registros de reuniões.

Para o tratamento dos dados, utilizou-se a técnica de análise de conteúdo, especificamente a análise estrutural, com vistas a identificar unidades significativas subjacentes aos enunciados (BARDIN, 2011). Observa-se que essa técnica auxilia a análise dos textos transcritos, desvelando núcleos de sentido existentes no discurso dos sujeitos para que, em seguida, sejam agrupados em categorias mais amplas (STRAUSS; CORBIN, 2008).

No que tange à organização e categorização dos dados, utilizou-se o software Atlas.ti, com o objetivo de "[...] cruzar os dados, buscando padrões e utilizando técnicas diferentes para possibilitar a observação do fenômeno através de múltiplas lentes" (EINSENHARDT, 1995, p. 75). O software favorece a elaboração de categorias para a investigação, de acordo com a proposta da análise de conteúdo (BANDEIRA-DE-MELLO, 2006).

Além das categorias levantadas, consideraram-se os dados com suporte no modelo de adaptação estratégica de Pettigrew (1987; 2012), que compreende a elaboração de análises por meio da leitura de três conceitos: "conteúdo", "contexto" e "processo" (Figura 1). Dessa forma, torna-se possível apreciar mudanças ocorridas na comunidade por meio das percepções sobre os principais eventos relacionados à implantação e ao funcionamento do parque eólico de Itarema, bem como realizar a análise histórica das informações contidas nos discursos e documentos.

Figura 1 - Triângulo de Pettigrew

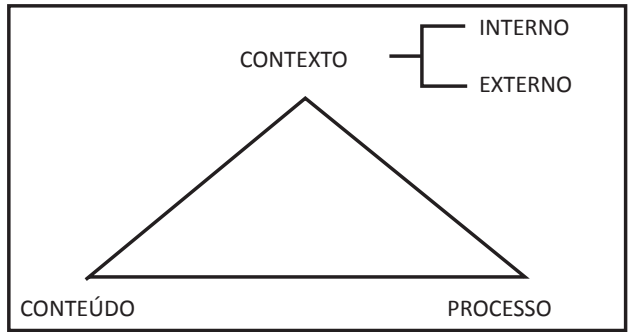

Fonte: Pettigrew (1987, p. 657). 
O processo descreve como ocorre a adaptação, ou seja, como o processo de mudança se associa às ações, reações e intenções dos sujeitos envolvidos na implantação da central de energia eólica nos municípios. O contexto define o porquê da mudança e divide-se em externo e interno. O contexto externo é entendido como as condições tecnológicas, condições sociais, políticas e econômicas externas à organização, as quais podem interferir na tomada de decisão dos gestores. E os aspectos do contexto interno são a estrutura organizacional, a cultura, as relações de poder e o contexto administrativo. Por fim, o conteúdo informa os aspectos que devem mudar na organização, como, por exemplo, os produtos e serviços. São os resultados dos impactos, das mudanças ocorridas com a implantação dos aerogeradores (PETTIGREW, 1987; 2012).

\section{Aspectos e caracterização dos Parques Eólicos}

O município de Acaraú localiza-se próximo à foz do rio Acaraú e distante 255 km de Fortaleza, e a cidade vizinha, Itarema, distante de Acaraú apenas 25 $\mathrm{km}$. A principal atividade econômica das comunidades desses dois municípios (Espraiado, Volta do Rio, Porto do Barco e Almofala) é a pesca artesanal.

Em Acaraú, instalou-se a Central Eólica Praia do Morgado, usina situada numa área de 366 hectares, com 19 aerogeradores de 1,5 MW. No caso de Itarema, a Central Eólica Pedra Cheirosa, de propriedade da empresa CPFL renováveis, possuirá potencial para $50 \mathrm{MW}$. Os empreendimentos foram desenvolvidos pela empresa ENERGIMP, subsidiária da IMPSA Energy.

A foz do Rio Acaraú é um lugar de alta viabilidade técnica e financeira para instalação de parques eólicos off-shore. Além do potencial de geração de energia eólica, a plataforma continental de Acaraú equivale à produção da maior usina hidroelétrica brasileira (ADECE, 2010).

Em Itarema, edificaram-se a Central Eólica Pedra Cheirosa, de propriedade da empresa CPFL renováveis, que possuirá potencial para $50 \mathrm{MW}$, e o complexo Eólico Itarema, formado por nove parques, quatro dos quais terão sua primeira operação comercial em 1 얼 de janeiro de 2016, e segunda operação em 30 de maio de 2016, de acordo com contrato firmado com a empresa Rio Energy (ANEEL, 2014).

\subsection{Análise das narrativas}

Numa perspectiva de investigação sobre os impactos sociais, ambientais e econômicos na construção e funcionamento dos parques eólicos situados nas cidades de Acaraú e Itarema, foram realizadas dez entrevistas, com suporte em roteiro semiestruturado, com dez moradores das comunidades de Volta do Rio, Praia do Morgado e Espraiado, comunidades circunvizinhas aos parques eólicos, durante o mês de março de 2015. As entrevistas foram gravadas e duraram, em média, 40 minutos.

Inicialmente, a codificação das entrevistas observou códigos que emergiram das diversas situações descritas pelos sujeitos entrevistados. Partiu-se de 
três categorias prévias de análise: impacto social, impacto econômico e impacto ambiental. Além dessas, considerou-se as análises de processo, de conteúdo e de contexto, relacionadas à implantação das empresas pesquisadas. De forma assessória, outras categorias foram inseridas no escopo da discussão dos dados, considerando a relevância dos enunciados para a pesquisa, bem como a repetição das falas, caracterizando a proposta de análise de conteúdo. Na Figura 2, pode-se observar a codificação das entrevistas, bem como a relação entre elas.

Figura 2 - Codificação das entrevistas

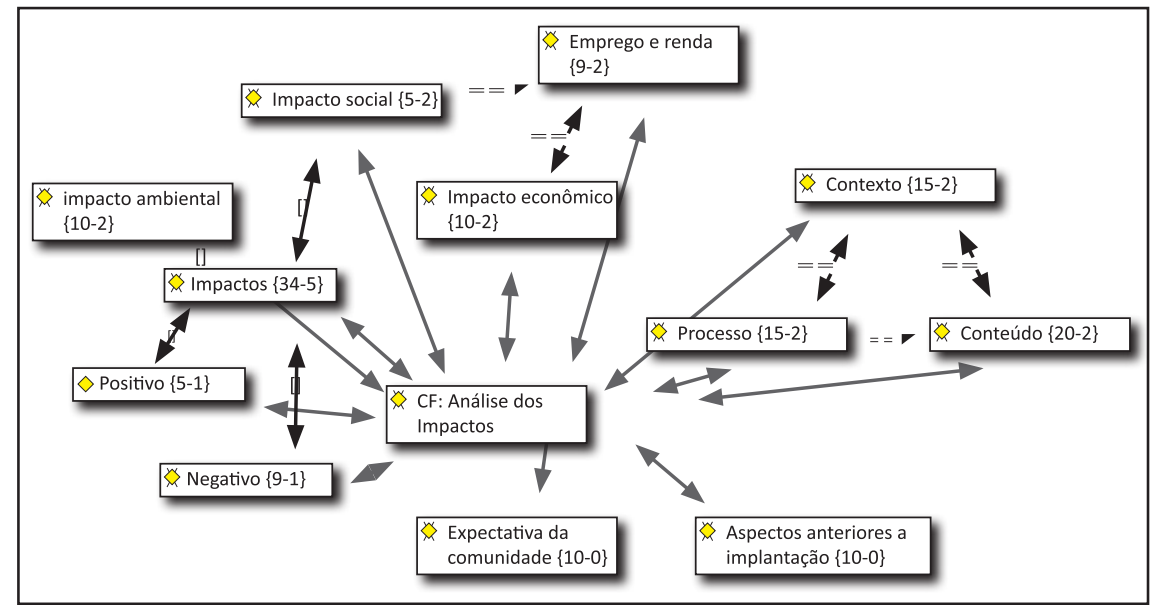

Fonte: Dados da pesquisa (2015).

A análise das categorias será iniciada pelo contexto de implantação das empresas; em seguida, o conteúdo que caracteriza esse movimento, bem como o processo subjacente ao funcionamento das usinas.

\subsection{A análise de contexto}

O contexto externo de implantação das usinas é intensamente favorável, haja vista incentivos do governo e o potencial energético da região atestados pela ADECE em 2014. No que tange ao contexto interno, abrangido pela inserção das usinas nas comunidades pertencentes aos municípios estudados, destacase que as empresas de produção de energia eólica foram construídas em terras pertencentes a famílias de posses, o que gerou frustrações, uma vez que havia a expectativa da comunidade circunvizinha de que as empresas pudessem servir a população menos favorecida. Além disso, a configuração expõe a fragilidade da relação desenvolvimento econômico e desenvolvimento local, em decorrência das expectativas associadas ao discurso empresarial capitalista de criação de empregos e movimentação da economia local (BANERJEE, 2008), assumindo o discurso do desenvolvimento sustentável, contrapondo-se à percepção da comunidade pós-implantação (REDCLIFT, 2006). 
Na realidade, no fundo no fundo, eles beneficiaram as classes mais altas, os latifundiários aí donos de terras que as torres caíram dentro, os pobres ai só receberam uma indenização de 800,700 reais $(E 3,2015)$.

Só pegaram as terras dos ricos, o meu exemplo mesmo, se esta obra viesse para cá, mais ou menos duas eólicas, ia pegar exatamente no nosso terreno só que não pegou, foi desviada, pegou subindo. Só pega os terrenos de ricos $(E 5,2015)$.

Assim, dos diálogos abstrai-se que há um contexto favorável à implantação, em decorrência das expectativas empresariais difundidas, com amparo na leitura capitalista, com base em promessas em torno do desenvolvimento econômico e social da região.

Prometeram ajudar, porque lá parte da estrada é carroçal, $3 \mathrm{~km}$ mais ou menos, muito buraco; no inverno, enche d'água, no verão, muita areia e poeira. Eles prometeram entrar em contato com a prefeitura para agilizar o calçamento, mas só prometeram, eu, como moradora de lá, digo que só prometeram (E2, 2015).

Prometeram quadra de esporte, eras escolas, melhorar a energia. Nada foi feito nem pela prefeitura nem por eles (E9, 2015).

Melhorava se tivesse colocado energia para a comunidade. A comunidade deixou colocar energia eólica, mas com direito à energia, e não aconteceu (E10, 2015).

Ainda sobre o contexto interno, há dois aspectos intrigantes sobre a construção das usinas: um deles diz respeito à falta de discussão com a comunidade; o outro, à dificuldade de manter um diálogo com as empresas sobre o processo de implantação e os impactos nas comunidades mais diretamente afetadas.

A chegada dos empreendimentos se deu sem comunicação prévia, sem que a proposta fosse analisada e discutida pelas comunidades. Isto posto, além das expectativas levantadas em consonância com uma cultura capitalista, o contexto de implantação indica falta de diálogo e de negociação, com imposição de mudanças assumidas pelos empresários como benéficas à população, o que reforça a leitura antropocêntrica, voltada aos interesses empresariais, unicamente (CARRIERI; 2003; INGOLD, 2000).

Quando foi construir na volta do Rio, a empresa foi apresentar, não foram debater, foram junto com a prefeitura só comunicar que ia ter o parque e, claro, mostrar algumas vantagens. Até porque a comunidade desinformada, ninguém entendia nada (E3, 2015).

Outro aspecto contextual da implantação das empresas refere-se à prática filantrópica como compensação à exploração de recursos da região, ao mesmo tempo em que envolve a premissa da sustentabilidade por meio das fontes de energias renováveis. 
Prometeram fazer um centro comunitário, até porque vinha muita gente, porque sempre usavam a escola, e não tem um local. Daí passaram 7, 8 anos e nada fizeram $(E 9,2015)$.

Prometeram ajudar, porque lá parte da estrada é carroçal, $3 \mathrm{~km}$ mais ou menos, muito buraco, no inverno, enche d'água; no verão, muita areia e poeira [...] Mas só prometeram, eu, como moradora de lá, digo que só prometeram (E10, 2015).

Assim, a narrativa indica que há, implícita no discurso, uma preocupação das empresas com a priorização da imagem da sustentabilidade com foco na vantagem econômica, portanto, capitalista (GOLDEMBERG; LUCON, 2007; SIMAS; PACCA, 2013), e centra esforços na harmonização dos anseios populares por meio de ações pontuais (BANERJEE, 2008).

Ainda no que diz respeito ao contexto, identifica-se a problemática das inter-relações complexas entre empresas, comunidades e meio ambiente, visando favorecer a comunicação de modo a oportunizar maior amplitude de conhecimento, no sentido de explorar possibilidades e desmistificar discussões pautados na sustentabilidade unicamente econômica (BRANDON, 1999; SINAY et al., 2013).

\subsection{A análise do processo}

O processo de implantação, no que tange ao desenvolvimento econômico e social, dá continuidade ao contexto de expectativas, numa perspectiva capitalista/ empresarial, quando ações compensatórias são veiculadas, agora, como ações de responsabilidade social, com base em um maior envolvimento dos empresários com as comunidades.

As empresas devem pensar não no agora na comunidade, na questão ambiental, social, já que eles não podem proporcionar nenhuma atividade de renda, financeira, já que o parque não necessita de muitas pessoas, eles desenvolverem pelo menos alguma atividade relacionada a isso $(E 7,2015)$.

Pelo relato, observa-se que ao processo de implantação veicula-se a ideia de que as empresas não podem comprometer-se com o desenvolvimento social e econômico da região, arraigado na premissa de que esse progresso é consequência da geração de empregos pelas usinas. Ao longo do processo, as expectativas transformam-se em frustrações, à medida que as comunidades vão percebendo que as empresas não possuem muito a oferecer em termos de meIhoria das condições de vida, associadas, basicamente, à oferta de empregos.

Ainda no escopo da responsabilidade social das empresas para com as comunidades, as ações pontuais e compensatórias são relatadas, como, por exemplo, algumas indenizações e um aumento do movimento do comércio durante a construção dos aerogeradores. Essas inciativas, por sua vez, são citadas como deduzidas em imposto de renda das empresas, ressaltando que a finalidade das atividades realizadas em prol da comunidade prima pelo capital econômico. 
O que eles fazem, o que eles promovem para a comunidade é deduzido no imposto, ele não está fazendo para minimizar o impacto que o parque fez e sim para benefício próprio. As pessoas que não entendem dizem que a empresa fez isso, isso e isso pela comunidade. Não, eles fizeram porque parte do lucro dela tem que ser gasto em prol comunidade, como lei já (E10, 2015).

Portanto, mais uma vez, depreende-se que, mesmo num contexto favorável às empresas, como o de facilitar o acesso e disponibilizar recursos ambientais, bem como menor mobilização comunitária em torno da implicação da região com os benefícios do negócio, a energia eólica é gerida com a mesma lógica que gera uma empresa concebida como não sustentável, embora compreenda a sustentabilidade como parte de seus processos (MEBRATU, 1998; REDCLIFT, 2006). Infere-se, portanto, que o negócio sustentável é fonte de lucratividade, por isso é visto como oportunidade, e, também, fonte de impactos sociais, quando mudanças no contexto de vida de populações são efetuadas; gera impactos econômicos, quando essas mudanças diminuem o acesso à renda, e, também, ambientais, por meio de alterações em sistemas naturais, para abrigar o lócus desses negócios.

Dessa reflexão, emerge o componente elementar da premissa capitalista, a concentração de renda e pouco, ou nenhum, desenvolvimento local (MEBRATU, 1998), à medida que as usinas, embora sejam empreendimentos de larga lucratividade e administradas por grandes empresas, dão retornos insignificantes às comunidades que abrigam os aerogeradores, quando se tem que a própria natureza do trabalho requer pouca mão de obra, sendo a empregabilidade o grande anseio dos moradores da região.

No que diz respeito ao processo analisado, sob a lente da sustentabilidade, as narrativas exploram diferentes impactos dos empreendimentos em relação ao cotidiano dos municípios. Os entrevistados retratam em novo cenário, marcado pela mudança da paisagem e alteração do estilo de vida e de trabalho.

Era mata fechada e tinha um campinho onde os meninos brincavam (E10, 2015).

Eu lembro que, quando eu era jovem, ia onde hoje é uma das eólicas e lá tinha lagos e rios grandes, onde muita gente se beneficiava de lá, o povo pescava e tirava o sustento de lá $(E 8,2015)$.

As transformações ressaltadas acompanham impactos ambientais, à medida que áreas florestais e manguezais foram alteradas para abrigar partes dos empreendimentos. Isto posto, percebe-se que o slogan da sustentabilidade face ao menor impacto ambiental, que sustenta o discurso pró-eólica, não desconstrói a leitura de que o desenvolvimento econômico se alinha, unicamente, à sustentabilidade das organizações e vantagens competitivas, sendo os investimentos em fontes renováveis de energia um negócio, acima de tudo, rentável, e a geração de menor impacto ambiental, secundário, e não abordado na dinâmica social (GOLDEMBERG; LUCON, 2007; BANERJEE, 2008). 


\subsection{Análise do Conteúdo}

Para caracterizar o conteúdo dos impactos sociais, econômicos e ambientais, os exemplos são enfatizados, à medida que denotam o teor concreto dessas mudanças e melhor configuram o cenário de estudo. Os exemplos são variados, desde a degradação do mangue e da vegetação ao incômodo causado pelos ruídos das torres. Alguns poucos postos de trabalho, gerados durante a implantação das empresas, não foram mantidos, e, além disso, pescadores perderam sua renda. Esses e outros impactos convergem para a leitura de Inatomi e Udaeta (2007), Barbosa Filho e Azevedo (2013) sobre os fatores negativos da produção de energia eólica, ressaltando a lógica empresarial do negócio sustentável e sobrepondo-se a questões específicas das comunidades circunvizinhas, o que pode indicar a quem se destina a sustentabilidade veiculada.

Hoje, se você for hoje lá, está tudo devastado, cheio de óleo, enfim, das torres (E2, 2015).

Porque lá tinha muito mangue, tinha marisco e peixes (E2, 2015).

Tem dia que incomoda. Não é todo dia, mas tem dia que, pelo amor de Deus! A pancada nas torres, quando ela está furada, dá aquele assobio (E2, 2015). Aí você chega lá, fala com segurança para mandar o guindaste, alguém vir consertar, passa dias. Porque realmente demora muito ser consertado, não é assim imediato, daqui que monte o guindaste vem não sei de onde, demora para montar, aí passa dias para consertar.

Vegetação foi retirada, porque tinha um acesso pequeno e foi retirado a mata (E4, 2015).

As torres foram colocadas na beira da praia, ali tinha a comunidade dependia, o pescador, a marisqueira que tirava parte do seu alimento, búzios, siris, caranguejo tudo isso tinha lá, e, com o parque, toda essa vegetação foi destruída. Então hoje não tem mais nada disso (E9, 2015).

Em relação à geração de empregos, os entrevistados informam que a natureza do negócio da energia eólica não consolida a abertura de um número expressivo de postos de trabalho. Oportunidades, no entanto, surgiram para o setor de vigilância e segurança. Para esses cargos, é exigida uma formação específica, incompatível com a escolaridade dos moradores da região e, também, indisponível à medida que não há instituições que ofertem cursos para as duas áreas. Por conseguinte, os residentes dessa região reforçam que as empresas deveriam assumir não apenas a oferta desses postos de trabalho, mas também a capacitação dos membros da comunidade para exercerem as atividades de que necessitam.

Eu me esforcei, gastei tempo e dinheiro para fazer o curso e eu moro dentro do parque e agora vejo pessoas de Acaraú e Itarema trabalhando. Deviam priorizar a comunidade $(\mathrm{E9}, 2015)$. 
Por fim, no que tange aos conteúdos que impactam a economia, o meio ambiente e o contexto social, questiona-se a responsabilidade social das empresas, tendo em vista que as usinas ocupam e modificam espaços, ocasionando múltiplas mudanças de vida dos grupos do entorno. Discute-se, também, que os membros da comunidade têm potencial, mas não possuem renda para buscar por conta própria os cursos necessários, e, quando o fazem, é fruto de um esforço pessoal que compromete a renda familiar.

A problemática apresentada se situa no espoco dos significados compartilhados sobre o que é ser sustentável, e, de forma prática, no que implicam suas ações, no sentido de reivindicar o status local do desenvolvimento, em prol da melhoria das condições de vida da sociedade, favorecendo o bem-estar social, com implicações que transcendam a lógica do capital e colaborem com práticas dissociadas do slogan sustentável, caminhando para uma identidade pró-ambiental, com gerenciamento comprometido com a realidade global e local (BANERJEE, 2008, REDCLIFT, 2006; SAHLINS, 1978).

\section{Considerações finais}

A investigação enfatizou a leitura sobre os impactos sociais, econômicos e ambientais sob as lentes do contexto, do processo e do conteúdo das mudanças advindas da implantação de empreendimentos de energia eólica em comunidades dos municípios de Acaraú e Itarema, Ceará.

No que diz respeito ao contexto de implantação, ressalta-se que o cenário para a energia renovável é favorecido pelo potencial eólico da região Nordeste, especialmente o estado do Ceará, em virtude de sua localização privilegiada no que tange aos ventos e ao deslocamento dos empresários para outras regiões do mundo. Além disso, a receptividade da região em relação às centrais eólicas foi incentivada com base no discurso da geração de empregos e renda, e, consequentemente, a melhoria das condições de vida da população. Em vista disso, o contexto foi favorecido pela oportunidade do negócio sustentável e pouca resistência para sua efetiva realização.

O processo de implantação revelou aspectos ocultados pelo discurso desenvolvimentista, em decorrência da afirmação do progresso como resultante da instalação de novas empresas. Com o tempo, os moradores foram adquirindo maior consciência sobre a natureza do trabalho realizado pelas empresas de energia eólica, haja vista o pequeno número de postos de trabalho oferecidos, e foram constatando também que as expectativas em torno dos empreendimentos não seriam atendidas.

Ainda em relação ao processo, identificou-se pouco envolvimento das empresas com as questões locais. Quando algumas ações eram desenvolvidas, atribuía-se à utilização de um recurso destinado por lei para atender requisitos de responsabilidade social, visando à lógica da lucratividade como norte para a execução das atividades em prol da comunidade.

No que diz respeito ao conteúdo das mudanças, os relatos indicam im- 
portantes impactos. No âmbito social, há mudanças no cotidiano das comunidades, em decorrência das transformações ambientais realizadas para atender à necessidade de espaços para a construção das usinas. O aspecto econômico sofreu com a diminuição de renda de famílias que viviam da pesca artesanal e de outras atividades correlatas, em decorrência da devastação do mangue. Por sua vez, o ambiente sofreu um importante impacto, à medida que gerou devastação da vegetação local e do manguezal, bem como impactos relacionados ao ruído das torres e do óleo utilizado para sua manutenção.

As comunidades influenciadas pelas empresas de energia eólica em estudo destacam, em geral, a insatisfação com o discurso ambientalista impregnado na vertente das energias renováveis, e, para tanto, discorrem sobre variadas situações que remetem à leitura de que não foi processado um maior planejamento para a implantação das usinas, especialmente no que diz respeito aos impactos ambientais, traduzidos na devastação ambiental e na ocorrência de ruídos.

Por fim, considera-se que a energia eólica, pertencente a um novo cenário ambiental, com foco em menor impacto ambiental, em comparação com outras fontes de energia não renováveis, transmite a ilusão de um recurso ambientalmente correto e livre de qualquer crítica ou reflexão. $O$ estudo indica que, mesmo aparentemente inofensivo, os empreendimentos remetem a novos impactos passíveis de novas possibilidades de reivindicação social. Nesse sentido, a "energia limpa" traz consigo inter-relações humanas e sociais, que merecem maior análise de uma política planejada em relação aos aspectos sociais, ambientais e aos impactos ambientais (MEIRELES, 2008; 2011; MEIRELES; SILVA; THIERS, 2006).

Devido ao uso apenas de dados primários oriundos da comunidade, sugerem-se futuras pesquisas, as quais explorem dados primários referentes a outros setores da economia das referidas cidades, como prefeitura; vereadores; os gestores dos parques eólicos; comerciantes das cidades e gestores do sistema de saúde.

\section{Referências}

ABRAMOWSKI, J.; POSORSKi, R. Wind energy in developing countries. DEWI Magazine, n. 16, p. 46-53, 2000.

ADECE. Atração de Investimentos no Estado do Ceará - Mapa Territorial de Parques Eólicos. Fortaleza: ENGEMEP, 2010.

ANEEL. Energia Eólica. Disponível em: <http://.www.adece.ce.gov.br/ index.php/ downloads/category/5-energia>. Acesso em: 29 out. 2014.

. Matriz energética do Brasil. Disponível em: <http://investimentos.mdic.

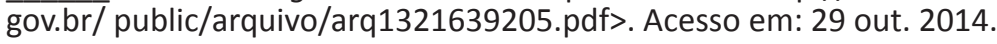

ARAÚJO, M.; FREITAS, M. Acceptance of renewable energy innovation in Brazil: case study of wind energy. Renewable and Sustainable Energy Reviews, n. 12, v. 2, p. 584-591, 2006. 
BANDEIRA-DE-MELLO, R. Softwares em pesquisa qualitativa. In: GODOI, C. K.; BANDEIRA-DE-MELLO, R.; SILVA, A. B. (Orgs.). Pesquisa Qualitativa em Estudos Organizacionais - Paradigmas, Estratégias e Métodos. São Paulo: Saraiva, 2006.

BANERJEE, S. B. Corporate Social Responsibility: The Good, the Bad and the Ugly. Critical Sociology, v. 34, n. 1, p. 51-79, 2008. Disponível em: <http://it.mesce. ac.in/ downloads/ProfessionalEthics/51.pdf>. Acesso em: 4 dez. 2014.

BARBIERI, J. C. et al. Inovação e sustentabilidade: novos modelos e proposições. Revista de Administração de Empresas, n. 50, v. 2, p. 146- 154, 2010.

BARBOSA FILHO, W. P.; AZEVEDO, A. C. S. de. Impactos ambientais em usinas eólicas. Itajubá: Agrener, 2013.

BARDIN, L. Análise de conteúdo. Lisboa: Edições 70, 2011.

BAUER; M. W.; GASKELL, G. Pesquisa qualitativa com texto, imagem e som - um manual prático. 5. ed. Petrópolis: Vozes, 2002.

BRANDON, P. S. Sustainability in management and organization: the key issues? Building Research e Information, n. 27, p. 6, p. 390-396, 1999.

BRASIL. Ministério de Minas e Energia. Empresa de Pesquisa Energética. Plano Decenal de Expansão de Energia 2020. Brasília: MME/EPE, 2011.

BRYCE, R. The high cost of wind energy as a carbon-dioxide reduction method. Manhattan Institute for Policy Research, n. 11, p. 1-9, 2011.

CARRIERI, A. P. O meio ambiente: discurso consistente ou prática vazia? Uma reflexão sobre os discursos ambientais, a teoria organizacional e o caso brasileiro. Revista de Administração Pública, v. 37, n. 6, p. 1209-1231, 2003.

COSTA, F. J. da et al. Valores pessoais e gestão socioambiental: um estudo com estudantes de administração. RAM, Revista de Administração Mackenzie, São Paulo, v. 14, n. 3, jun. 2013. Disponível em: <http://www.scielo.br/scielo. php?script=sci_arttext\&pid=S1678-69712013000300008\&lng=en\&nrm=iso>. Acesso em: 30 nov. 2014.

EINSENHARDT, K. M. Building Theories From Case Study Research. In: HUBER, G. P.; VAN de VEN, A. H. Longitudinal Field Research Methods - Studying Processes of Organizational Change. Thousand Oaks: Sage Publications, 1995.

FONTENELE, R. E. S.; SOUZA, S. D. A Energia Eólica do Estado do Ceará e o Mecanismo de Desenvolvimento Limpo do Protocolo de Quioto. In: XLII Congresso da Sociedade Brasileira de Economia e Sociologia Rural - SOBER, 2004, Cuiabá - MT. Dinâmicas Setoriais e Desenvolvimento Regional, 2004.

GOLDEMBERG, J.; LUCON, O. Energia e meio ambiente no Brasil. Estudos Avançados, v. 21, n. 59, p.7-20, 2007.

GONCALVES-DIAS, S. L. F.; HERRERA, C. B.; CRUZ, M. T. de S. Desafios (e dilemas) para inserir "Sustentabilidade" nos currículos de administração: um estudo de caso. RAM, Revista de Administração Mackenzie, São Paulo, v. 14, n. 3, jun. 2013. Disponível em: <http://www.scielo.br/scielo.php?script=sci_arttext\&pid=S167869712013000300006\&lng=en\&nrm=iso>. Acesso em: 30 nov. 2014. 
HOPKINS, C. Twenty years of education for sustainable development. Journal of Education for Sustainable Development, 2012, n. 6, v. 1. 2012. Disponível em: <http://jsd.sagepub.com/content/6/1/1.full.pdf>. Acesso em: 29 nov. 2014.

INATOMI, T. A. H.; UDAETA, M. E. M. Análise dos impactos ambientais na produção de energia dentro do planejamento integrado de recursos. São Paulo: USP, 2007. Disponível em: <http://seeds.usp.br/portal/uploads/INATOMI_TAHI_ IMPACTOS_AMBIENTAIS.pdf>. Acesso em: 10 nov. 2014.

INGOLD, T. Perceptions of environment: essays on livelihood, dwelling and skill. Londres; Nova lorque: Routledge, 2000.

LAGE, A. C.; BARBIERI, J. C. Avaliação de projetos para o desenvolvimento sustentável: uma análise do Projeto de Energia Eólica do Estado do Ceará com base nas dimensões da sustentabilidade. Anais do Encontro Anual da Associação Nacional dos Programas de pós-graduação em Administração, XXV EnANPAD. Campinas: ANPAD, 2001.

LASH, J. WELLINGTON, F. Competitive advantage on a warming planet. Harvad Business Review, março, 2007. Disponível em: <http://www. climateactionproject. com/docs/Competitive_Advantage_Warming_Planet.pdf $>$. Acesso em: 22 nov. 2014.

MARCONATTO, D. A. B. et al. Saindo da trincheira do desenvolvimento sustentável: uma nova perspectiva para a análise e a decisão em sustentabilidade. RAM, Revista de Administração Mackenzie, São Paulo, v. 14, n. 1, fev. 2013. Disponível em: <http://www.scielo.br/scielo.php?script=sci_ arttext\&pid=S1678-69712013000100002

\&lng=en\&nrm=iso>. Acesso em: 30 nov. 2014.

MEBRATU, D. Sustainability and sustainable development: historical and conceptual review. Environ Impact Asses Rev. n. 18, p. 493-520, 1998. Disponível em: <http://www.is.cnpm.embrapa.br/bibliografia/1998_Sustainability_and_ sustainable_development_Historical_and_conceptual_review.pdf $>$. Acesso em: 21 nov. $201 \overline{4}$.

MEIRELES, A. J. de A. Danos socioambientais originados pelas usinas eólicas nos campos de dunas do Nordeste Brasileiro e critérios para definição de alternativas locacionais. Confins. Revue franco-brésilienne de géographie/ Revista franco-brasilera de geografia, n. 11, 2011.

. Impactos ambientais decorrentes da ocupação de áreas reguladoras do aporte de areia: a planície Costeira da Caponga, município de Cascavel, litoral leste cearense. Confins. Revue franco-brésilienne de géographie/Revista franco-brasilera de geografia, n. 2, 2008.

MEIRELES, A. J. A., SILVA, E. V.; THIERS, P. R. L. Os campos de dunas móveis: fundamentos dinâmicos para um modelo integrado de planejamento e gestão da zona costeira. Espaço e Tempo, São Paulo, n. 20, p. 101-119, 2006.

MELO, E. Fonte eólica de energia: aspectos de inserção, tecnologia e competitividade. Estudos Avançados, São Paulo, v. 27, n. 77, 2013. Disponível em: <http://www.scielo.br/scielo.php?script=sci_arttext\&pid=S0103$40142013000100010 \&$ Ing=pt\&nrm=iso>. Acesso em: 29 out. 2014. 
MINAYO, M. C. de S. O desafio do conhecimento - Pesquisa qualitativa em saúde. São Paulo: Hucitec, 2007.

MOREIRA, R. N. et al. Energia eólica no quintal da nossa casa?! Percepção ambiental dos impactos socioambientais na instalação e operação de uma usina na comunidade de sítio do Cumbe em Aracati - CE. Revista de Gestão Ambiental e Sustentabilidade - GeAS, São Paulo, v. 2, n. 1, p. 47-74, jan./jun. 2013. Disponível em: <http://www.revistageas.org.br/ ojs/index.php/geas/article/ view/39>. Acesso em: 4 nov. 2014.

NASCIMENTO, T. C., MENDONÇA, A. T. B. de; CUNHA, S. K. da. Inovação e sustentabilidade na produção de energia: o caso do sistema setorial de energia eólica no Brasil. Cadernos EBAPE.BR, v. 10, n. 3, p. 630-651, 2012.

OLIVEIRA, Y. C. L.. Estudo da geração de energia elétrica através do parque eólico do Ceará. Monografia (Curso de Engenharia Elétrica) - Universidade Federal de Viçosa, Viçosa, 2011.

PATTON, M. Q. Qualitative Research and Evaluation Methods. 3. ed. Thousand Oaks: Sage, 2002.

PEARSON EDUCATION DO BRASIL. Gestão Ambiental. São Paulo. Pearson Prentice Hall, 2011.

PETTIGREW, A. Context and action in the transformation of the firm. Journal of Management Studies, v. 24, n. 6, p. 649-670, 1987. Disponível em:

<http://onlinelibrary.wiley.com/doi/10.1111/j.1467-6486.1987.tb00467.x/pdf>. Acesso em: 2 fev. 2013.

. Context and action in the transformation of the firm: A Reprise. Journal of Management Studies, v. 49, n. 7, p. 1304-1328, nov. 2012. Disponível em: <http://onlinelibrary.wiley.com/doi/10.1111/j.1467-6486.2012.01054.x/pdf>. Acesso em: 3 fev. 2013.

REDCLIFT, M. R. Sustainable development (1987-2005): an oxymoron comes of age. Horizontes Antropológicos, Porto Alegre, v. 3, Selected Edition, 2006. Disponível em: <http://socialsciences.scielo.org/scielo.php?script=sci arttext\&pid=S0104-71832007000100002\&lng=en\&nrm=iso >. Acesso em: 20 out. 2014.

SACHS, I. Caminhos para o desenvolvimento sustentável. Rio de Janeiro: Garamond, 2000.

SAHLINS, M. Stone Age Economics. London: Tavistock Publications, 1978.

SAMPIERI, R. H.; COLLADO, C. F.; LUCIO, P. B. Metodologia de Pesquisa. São Paulo: McGraw Hill, 2006.

SIMAS, M.; PACCA, S. Energia eólica, geração de empregos e desenvolvimento sustentável. Estudos Avançados, São Paulo, v. 27, n. 77, 2013. Disponível em: <http://www.scielo.br/scielo.php?script=sci_arttext\&pid=S0103$40142013000100008 \&$ Ing=pt\&nrm=iso >. Acesso em: 29 out. 2014. 
SINAY, M. C. F. de et al. Ensino e pesquisa em gestão ambiental nos programas brasileiros de pós-graduação em administração. RAM, Revista de Administração Mackenzie, São Paulo, v. 14, n. 3, jun. 2013. Disponível em: <http://www.scielo. $\mathrm{br} / \mathrm{scielo}$.php?script=sci_arttext\&pid=S1678-69712013000300004\&lng=en\&nrm =iso>. Acesso em: 21 nov. 2014.

STRAUSS, A.; CORBIN, J. Pesquisa Qualitativa: Técnicas e procedimentos para o desenvolvimento da teoria fundamentada. 2. ed. Porto Alegre: Artmed, 2008.

SULAIMAN, S. N. Educação ambiental, sustentabilidade e ciência: o papel da mídia na difusão de conhecimentos científicos. Ciência e Educação, Bauru, v. 17, n. 3, 2011. Disponível em: <http://www.scielo.br/scielo.php?script= sci_arttext\&pid=S1516-73132011000300008\&lng=pt\&nrm=iso>. Acesso em: 29 nov. 2014. 